\title{
A ILEGALIDADE NA LEI No . 13.296/2008: A QUESTÃO DO DOMICÍLIO CONCERNENTE ÀS LOCADORAS E CONCESSIONÁRIAS DE VEÍCULOS
}

\author{
ILLEGALITY IN THE LAW NUMBER 13.296/2008: THE \\ DOMICILE QUESTION CONCERNING TO RENTAL AND \\ DEALERSHIP OF VEHICLES
}

\author{
Luana Madureira dos Anjos ${ }^{1}$ \\ Natália Jodas ${ }^{2}$ \\ Vitor José Tozzi Cavina ${ }^{3}$
}

\begin{abstract}
RESUMO: O Imposto sobre a Propriedade de Veículos Automotores (IPVA) é um tributo de existência relativamente nova no Sistema Tributário Brasileiro. Após análise do surgimento e evolução do tributo no país, analisar-se-ão suas particularidades no que concerne aos critérios que informam sua regra matriz de incidência tributária, especialmente as que tomam maior importância para o presente estudo. Desta forma, no trabalho são abordados os critérios material e temporal da hipótese de incidência, deixando para um momento posterior, quando do estudo do critério pessoal da relação jurídica tributária, a análise do critério espacial. Na seqüência, abordar-se-á o problema relacionado à competência dos Estados-membros para instituição e cobrança do imposto, devido à falta de Lei complementar para disciplinar a matéria. Devido a esta lacuna no ordenamento jurídico, será explicitada a necessidade do Direito Tributário de valer-se de matéria disciplinada em Diplomas de outros ramos do Direito, principalmente no Código Civil e Código de Trânsito Brasileiro. Analisar-se-á, então, a disciplina do domicílio no Direito pátrio e sua relevância para a interpretação da Lei 13.296/2008 do Estado de São Paulo que regula as matérias referentes ao Imposto sobre a Propriedade de Veículos Automotores neste Estado, em especial no tratamento destas normas em relação às empresas locadoras de veículos. Alguns dispositivos da referida legislação tributária, como se demonstrará neste trabalho, violaram institutos delineados por normas de caráter nacional, o que afeta, de pronto, a sua legalidade.
\end{abstract}

Palavras-Chave: IPVA; Critério espacial; Domicílio; Legislação paulista; Ilegalidade.

\begin{abstract}
The Tax on Motor Vehicles (IPVA) is a relatively new tribute in Brazilian Tax System. After analyzing the emergence and evolution of the tax in the country; will be analyzing its merits in relation to the criterion that give bases in it's rule, specially those whom importance is crucial to this study. In a second moment, the work examines the criteria of material and temporal impact hypothesis, leaving to a later time, when the study of the criterion of personal tax relationship, analysis of the spatial criterion of the tax. Subsequently, it will address the problem related to the competence of Member States for establishment and collection of tax due to lack of supplementary law to govern the matter. Due to this gap in the legal system, will be outlined the need for the Tax Law to rely matter disciplined Diplomas

${ }^{1}$ Aluna de Direito do $5^{\circ}$ ano da Universidade Estadual de Londrina.

${ }^{2}$ Aluna de Direito do $5^{\circ}$ ano da Universidade Estadual de Londrina.

${ }^{3}$ Aluna de Direito do $5^{\circ}$ ano da Universidade Estadual de Londrina.
\end{abstract}


other branches of law, especially in the Civil Code and the Brazilian Traffic Code. Analyze will then address the discipline of law in the homeland and its relevance for the interpretation of Law 13.296/2008 of Sao Paulo State which regulates matters pertaining to the Tax on Motor Vehicles in this state, especially in treatment of these standards in relation to rental car companies. Some devices of this tax legislation, as will be shown in this work, violated standards outlined by institutes of national character, which affects it's legality.

Key-Words: IPVA; Spatial criterion; Domicile; Paulista legislation; Illegality.

\section{INTRODUÇÃO}

A cobrança do IPVA - Imposto sobre a Propriedade de Veículos Automotores - é alvo de intensas disputas dentre os Estados brasileiros, os quais, por sua vez, nos limites de seus territórios, figuram como os entes federados competentes para tanto.

Assim, cada um dos Estados-membros da Federação, bem como o Distrito Federal, perquirindo maior produto na arrecadação de tributos, busca atrair para si a competência para a exação do IPVA, editando leis que, por muitas vezes, não só não apresentam fundamento no ordenamento jurídico brasileiro, como também contrariam preceitos ali já edificados.

Essa verdadeira "guerra fiscal" existente entre os Estados-membros é agravada ainda pelo fato de não haver, no ordenamento jurídico brasileiro, lei complementar que estabeleça normas gerais relativas ao IPVA, capaz de solucionar os conflitos gerados quando da edição das legislações estaduais para a instituição do IPVA em cada Estado.

Tendo isso em vista, e diante da importância do tema na atual conjuntura jurídicotributária do país, o presente trabalho dedicar-se-á à análise do critério para a definição do domicílio de empresas locadoras e concessionárias prescrito pela Lei nº 13.296/2008 do Estado de São Paulo, verificando-se a existência de ilegalidade quando da sua definição.

\section{IMPOSTO SOBRE A PROPRIEDADE DE VEÍCULOS AUTOMOTORES (IPVA)}

O Imposto sobre a Propriedade de Veículos Automotores (IPVA) surgiu no ordenamento brasileiro em 1985, substituindo a Taxa Rodoviária Única (TRU), que era regida pelo Decreto-lei 999/1969 e cobrada pela União na renovação anual da licença para o veículo circular ou no registro desse.

Assim, por meio da Emenda Constitucional 27/85, que acrescentou o inciso III ao 
artigo 23 da Constituição Federal de 1967, nasce o Imposto sobre a Propriedade de Veículos Automotores, autorizando os Estados e o Distrito Federal a instituí-lo, os quais elaboraram leis estaduais para a sua aplicação, na medida em que não se exigia, à época, a existência de lei complementar para tanto e, por ser imposto novo, não se encontrava regido pelo Código Tributário Nacional.

Com o advento da Constituição Federal de 1988, o IPVA passa a ser previsto no seu artigo 155, inciso III, mantendo a competência dos Estados e do Distrito Federal para a instituição de impostos sobre a propriedade de veículos automotores.

Ocorre que a atual Constituição Federal brasileira, diferentemente da anterior, exige que as normas gerais em matéria de legislação tributária devam ser estabelecidas por meio de lei complementar (artigo 146, inciso III), isto é, como explica Rogério Martins (2007, p. 748), o imposto só poderia ser cobrado pelo sujeito ativo se anteriormente "definido em linhas gerais (contribuinte, fato gerador, base de cálculo etc), por lei complementar". Porém, no que concerne ao Imposto sobre a Propriedade de Veículos Automotores, não existe referida lei no ordenamento jurídico brasileiro.

Todavia, a ausência de lei complementar em relação ao IPVA não significa que a sua cobrança não possa existir, vez que o artigo 34, parágrafo $3^{\circ}$, do Ato das Disposições Constitucionais Contrárias (ADCT) - que estabelece que os entes federados "poderão editar as leis necessárias à aplicação do sistema tributário nacional” -, bem como o artigo 24, parágrafo $3^{\circ}$, da Constituição Federal de 1988 - o qual determina que na ausência de lei federal sobre normas gerais, os Estados desempenharão competência plena, atendendo às suas peculiaridades -, evidenciam a legitimidade dos Estados-membros para a edição de leis ordinárias que ditem as regras gerais a respeito do IPVA, no alcance de seus territórios.

Nesse sentido, face à inexistência de lei complementar que regule a aplicação do IPVA, e tendo a Constituição Federal atribuído competência aos Estados e ao Distrito Federal para a instituição desse imposto (artigo 155, inciso III), verifica-se a presença de autorização constitucional para que cada Estado-membro, nos limites de seu território, legisle, apontando a hipótese de incidência tributária, o sujeito passivo, a base de cálculo e a alíquota, podendo ser realizada a sua cobrança. Ou seja, cabe a cada Estado-membro, enquanto não advenha lei complementar da União, nos termos do parágrafo $3^{\circ}$ do artigo 24 da Constituição Federal de 1988, a edição de leis ordinárias estaduais que determinem a hipótese de incidência tributária e a relação jurídica tributária, e, por conseqüência, a regra-matriz de incidência tributária (norma jurídica tributária), elucidada pelo doutrinador Paulo de Barros Carvalho (2008, p. 376). 
Dessa feita, a competência tributária, como ensina Carrazza (2009, pp. 506, 508), é a aptidão, a permissão, o direito subjetivo - delegado pela Constituição - que possui cada ente federativo de criar, in abstracto, tributos, isto é, de descrever legislativamente e de maneira pormenorizada a norma jurídica tributária, nos limites impostos tanto pelas normas quanto pelos princípios constitucionais.

Em sendo assim, cada Estado-membro, ao criar a sua norma jurídica tributária para o IPVA, está exercendo a sua competência tributária delegada pela Constituição Federal. E, exatamente por serem os Estados-membros meros delegados pela Constituição para o exercício do direito subjetivo de editar a norma jurídica tributária do IPVA, "não têm poderes para alterarem as faculdades tributárias que lhes foram atribuídas pela Carta Suprema” (CARRAZA, 2009, p. 508), sendo que essa, ao estipular as competências tributárias, já determinou, de certa forma, a regra-matriz de incidência de cada tributo, ou seja, os possíveis sujeito ativo, passivo, base de cálculo, alíquota e hipótese de incidência (CARRAZA, 2009, p. 516).

Nesse liame, os Estados-membros, quando da edição de leis ordinárias para a criação, in abstracto, do IPVA, quer dizer, da norma jurídica tributária desse imposto, de maneira que possa ser cobrado, devem respeitar a regra-matriz de incidência tributária já estabelecida constitucionalmente, a qual será objeto de estudo do próximo tópico.

\section{A regra-matriz de incidência tributária: análise do critério material}

A Regra-Matriz de incidência tributária, elaborada pelo doutrinador Paulo de Barros Carvalho (“Curso de Direito Tributário") é, nas palavras do próprio autor (2008, p. 375), “norma de conduta, vertida imediatamente para disciplinar a relação do Estado com seus súditos, tendo em vista contribuições pecuniárias", apresentando esquema formal apto "para retratar o fenômeno do impacto de todo e qualquer tributo." (CARVALHO, 2008, p. 376).

Portanto, é a regra-matriz de incidência tributária norma jurídica tributária, sendo geral e abstrata, apresentando em seu antecedente a hipótese de incidência tributária (linguagem prescritiva geral e abstrata do fato) - formada pelos critérios material, espacial e temporal - e em seu conseqüente a relação jurídica tributária - formada pelo critério pessoal, que é constituído pelos sujeitos ativo e passivo, e critério quantitativo, por sua vez composto pela base de cálculo e alíquota.

Nessa estrutura tem-se que, quando realizada a hipótese de incidência tributária, concretizando-se os fatos ali descritos, isto é, quando o fato jurídico tributário (projeção factual da 
hipótese de incidência tributária) submete-se à hipótese tributária, deve ser a conseqüência, que é a relação jurídica tributária formada a partir de então, na qual se encontra o sujeito passivo obrigado a cumprir uma prestação em dinheiro ao sujeito ativo, que, por sua vez, possui direito subjetivo de exigir tal prestação pecuniária.

Ocorre que, para que haja um bom entendimento do tema abordado no presente trabalho, não se poderão estudar os elementos da regra-matriz de incidência tributária na ordem em que essa se dá, conforme explicado acima. Assim, para que seja atingido o objetivo buscado, serão brevemente analisados, em um primeiro momento, os critérios material e temporal da hipótese de incidência do IPVA - Imposto sobre a Propriedade de Veículos Automotores - ambos pertencentes à hipótese de incidência, como já se sabe -, sendo em seguida analisado o critério pessoal da relação jurídica tributária, para que então se possa explicar o critério espacial da hipótese de incidência tributária, correlacionando-o com o sujeito ativo, tendo em vista que o entendimento desses é de fundamental importância para os objetivos aqui almejados. Por isso mesmo, não se dedicará o presente trabalho ao estudo do critério quantitativo, isto é, da base de cálculo e da alíquota do IPVA, já que não é imperioso para o alcance dos fins desejados.

Nesse passo, a hipótese de incidência tributária, como explicado acima, é formada pelos critérios material, espacial e temporal. O critério material, como ensina Paulo de Barros Carvalho (2008, p. 377), é o "núcleo da descrição fática”, constituído pelo verbo somado ao seu complemento. Assim, faz-se necessário transcrever o artigo 155, inciso III, da Constituição Federal de 1988, segundo o qual:

Art. 155. Compete aos Estados e ao Distrito Federal instituir impostos sobre: III - propriedade de veículos automotores

Pois bem, da dicção do artigo transcrito acima verifica- se que o critério material do IPVA é ser proprietário (verbo) de veículo automotor (complemento), sendo que tal propriedade é provada por meio do Certificado de Registro de Veículo (SABBAG, 2004, P. 307). Não é de interesse deste trabalho dedicar-se ao estudo do alcance do termo "veículo automotor" no que tange à possibilidade de entender-se esse como sendo, além de terrestre, aquático e aéreo, questão que vem provocando acirradas discussões na doutrina e jurisprudência, de maneira que se faz imperioso apenas observar que aqui, quando se fizer referência a tal termo, deve-se ter em mente a sua modalidade terrestre.

Por sua vez, o critério temporal, isto é, a "condicionante de tempo" (CARVALHO, 2008, P. 377), o momento em que ocorre o fato imponível do IPVA - que é a propriedade do ve- 
ículo automotor -, dar-se-á de acordo com o estipulado em cada legislação estadual que regule o referido imposto. Porém, certo é que o critério temporal variará de acordo com as formas de ocorrência do fato imponível, que podem ser divididas em três (SILVA, 2006, p. 149), tendo em vista ser o veículo novo, usado ou importado.

Assim, no caso de veículo novo, há ocorrência originária do fato imponível, que acontece na data em que o veículo é adquirido pelo consumidor ou, em se tratando de pessoa jurídica, quando o veículo passar a constituir seu ativo permanente. Quando se tratar de veículo usado, deve-se considerar ocorrido o fato imponível no dia $1^{\circ}$ de janeiro de cada exercício financeiro. E, ainda, em se tratando de veículo importado, tem-se que, se a importação for realizada por consumidor final, a ocorrência do fato imponível dar-se-á na data do desembaraço aduaneiro e, no caso de a importação ser promovida por comerciante ou fabricante, com o objetivo de revender o veículo, considera-se esse veículo novo, ocorrendo, portanto, o fato imponível do IPVA quando da sua aquisição por consumidor ou incorporação no ativo permanente de pessoa jurídica.

Dessa forma, devidamente analisados o critério material e temporal da hipótese de incidência do IPVA, passa-se ao estudo do critério pessoal da relação jurídica tributária, o qual, como visto, é formado pelos sujeitos ativo e passivo.

Muito bem, o sujeito passivo da relação jurídica tributária é o contribuinte, aquele que tem o dever, a obrigação de pagar o tributo ao sujeito ativo, o qual, por sua vez, tem o direito subjetivo, a prerrogativa de receber esse pagamento. Nesse passo, e de acordo com o estudado até o presente momento, já se é possível perceber que o sujeito passivo, o contribuinte do IPVA, será a pessoa física ou jurídica proprietária de veículo automotor (MAMEDE, 2002, p. 109).

Os sujeitos ativos do IPVA, a seu tempo, aqueles que possuem o direito subjetivo de exigir a prestação pecuniária referente ao imposto em questão serão os Estados-membros e o Distrito Federal nos limites de seu território, já que conforme explicado em tópico anterior, e, de acordo com o artigo 155, inciso III, da Constituição Federal de 1988, possuem eles competência para instituir o IPVA.

Dessa feita, resta, neste momento, a análise do critério espacial, da "condicionante de lugar" (CARVALHO, 2008, p. 377), isto é, do espaço físico no qual a relação jurídica tributária possa vir a existir, sendo esse considerado o local onde estiver registrado o veículo automotor, que corresponde, por sua vez, ao território do Estado-membro competente ou Distrito Federal (artigo 155, inciso III, da Constituição Federal), isto é, ao território do sujeito ativo.

Entretanto, a discussão existente firma-se justamente quando da definição do Estadomembro em que se deve dar o registro e licenciamento do veículo automotor, o que, por sua vez, 
tornará possível a identificação de um ou outro Estado-membro como sujeito ativo da relação jurídica tributária do imposto sobre a propriedade de determinado veículo automotor, em outras palavras, como o sujeito competente para a cobrança do IPVA (Imposto sobre a Propriedade de Veículo Automotor) de certo veículo automotor, nos limites de seu território.

Nesse passo, já se pode perceber que a análise do critério espacial do IPVA não é tarefa simples, isso devido ao fato de ser um imposto que incide sobre a propriedade de um bem que possui como característica inerente a mobilidade, provocando constantes conflitos de competência para o seu recolhimento entre os Estados-membros, agravados pelo fato de não existir uma lei complementar, nos termos do artigo 146, inciso I, da Constituição Federal, capaz de solucioná-los.

Dessa maneira, percebe-se que a falta de lei complementar que discipline o IPVA fazse gritante quando o assunto é o critério espacial desse imposto, ou seja, quando se trata de localizar o Estado-membro em que poderá ser exigida a prestação pecuniária referente a esse imposto, e, por conseqüência, o sujeito ativo da relação jurídica que se estará formando no território de tal Unidade Federativa, sendo que, na medida em que resta a esses mesmos legislar sobre o assunto, é formada uma verdadeira guerra fiscal entre os Estados brasileiros, com legislações muitas vezes esdrúxulas e abusivas.

Nesse sentido, importante verificar a regra existente no Código de Trânsito Brasileiro (lei 9.503/1997) relativa ao registro de veículo automotor, contida em seu artigo 120, o qual determina que todo o veículo automotor "deve ser registrado perante o órgão executivo de trânsito do Estado ou do Distrito Federal, no Município de domicílio ou residência de seu proprietário, na forma da lei."

Com isso, diante da redação do referido artigo 120 do Código de Trânsito Brasileiro, evidencia-se que o registro do veículo deve ser realizado no local do domicílio ou residência de seu proprietário, de acordo com o disposto em lei. Ora, sabe-se que a lei que dispõe sobre domicílio e residência é o Código Civil, cujos artigos que tratam desse assunto serão devidamente estudados no presente trabalho.

Tendo isso em vista, faz-se impreterível, neste momento, observar que, muitas vezes, as normas constantes no Código Civil referentes ao domicílio nem sempre são respeitadas quando se trata de estabelecer os critérios para a competência tributária, já que muitos Estados, objetivando maior produto na arrecadação de tributos, acabam por editar leis com critérios próprios no estabelecimento do domicílio do proprietário do veículo automotor, sem qualquer fundamento constitucional ou legislativo. E é o objetivo deste trabalho a análise de uma legislação, 
qual seja da lei no 13.196/2008 do Estado de São Paulo, que contém critérios como esses para a identificação do sujeito ativo da relação jurídica da norma de incidência tributária do IPVA.

\section{DOMICÍLIO TRIBUTÁRIO: ASPECTOS GERAIS}

Domicílio é a localidade onde a pessoa estabelece residência com ânimo definitivo. É a sede jurídica da pessoa, ou seja, é onde o sujeito estabelece a sede de suas atividades (AMARAL, 2003, p. 246). O Código Tributário Nacional (Lei 5.172/66) estabelece em seu art. 127, caput, primeiramente, a permissão legislativa para a escolha do foro do domicílio tributário por parte do contribuinte, conforme a "legislação aplicável".

Desta feita, da redação do caput do referido artigo, pode-se extrair que, quando o legislador prescreve "na falta de eleição, pelo contribuinte ou responsável, de domicílio tributário", foi concedida ao sujeito passivo da relação jurídica tributária a faculdade de escolher seu domicílio, pois, só na "falta de eleição" é que se deve observar a prescrição legal trazida pelos incisos que se seguem. O contribuinte poderia, então, dispor sobre o local de sua preferência.

Questão controversa recai sobre qual legislação seria aplicável para eleição do domicílio. Há quem acredite que não há legislação específica aplicável a amparar o contribuinte na escolha do domicílio e, por isso, este estaria impedido de exercer seu direito de eleição.

Porém, parece mais prudente considerar "legislação aplicável" aquela que abriga, em caráter geral, o instituto do Domicílio no ordenamento jurídico. No caso do Brasil, esta legislação seria o Código Civil de 2002 que, em seu art. 70 e seguintes, estabelece as regras para o domicílio das pessoas naturais e jurídicas.

Este diploma legal define, em seu art. 71, que a pessoa natural pode ter uma pluralidade de residências, sendo justo considerar qualquer delas como seu domicílio. Desta forma, o Direito Tributário utiliza-se das atribuições dadas por outro ramo do Direito pátrio ao instituto para suprir a falta de legislação específica, principalmente no tocante à pluralidade e possibilidade de escolha do domicílio.

Quanto às pessoas jurídicas, em particular as de direito privado, o Código Civil, em seu artigo $75, \S 1^{\circ}$, considera qualquer um dos estabelecimentos, caso estejam localizados em lugares diferentes, como domicílio.

Sendo o Código Tributário Nacional (CTN) legislação de caráter nacional e geral, suas disposições não poderiam ser suprimidas por legislações regionais ou específicas para uma determinada situação tributária. É o que tem ocorrido com a Lei 13.296/2008 do Estado 
de São Paulo, que trata de forma diversa à prescrita no Código Tributário Nacional a questão do domicílio do contribuinte do Imposto sobre a Propriedade de Veículos Automotores (IPVA), conforme será tratado no item a seguir.

\section{A LEI ESTADUAL DE SÃO PAULO Nº $\mathbf{1 3 . 2 9 6 / 2 0 0 8}$}

A Lei Estadual nº 13.296 de 23 de Dezembro de 2008, vigente no Estado de São Paulo há alguns meses, substituiu a antiga lei $\mathrm{n}^{\mathrm{o}}$. 6.606/1989 que dispunha a respeito do IPVA- Imposto sobre a Propriedade de Veículos Automotores - arrecadado no Estado. A nova lei surgiu de certa forma para viabilizar a operação paulista "De Olho na Placa", atividade desenvolvida pelas Secretarias da Segurança Pública e da Fazenda (Sefaz-Sp) a partir do final do ano de 2007, tendo como um dos principais objetivos a verificação da regularidade do licenciamento dos veículos em circulação no estado e a possível identificação de veículos com CRLV - Certificado de Registro e Licenciamento de Veículos - emitido com base em declaração falsa de domicílio, demonstrando ser tal instrumento um meio eficaz de combate à perda de arrecadação de IPVA.

A justificativa dada à engrenagem da operação supracitada arraiga-se à perda de aproximadamente quinhentos milhões de reais ao Tesouro do Estado nos últimos cinco anos, o que, segundo declarações da própria Secretaria da Fazenda, tal evasão fiscal vincula-se diretamente às constantes fraudes na declaração de domicílio dos contribuintes, que optam por Estados da Federação cujas alíquotas do IPVA são mais baratas. O fato do Estado de São Paulo possuir a alíquota mais cara do país, em regra $4 \%$ (quatro por cento) sobre o valor venal do veículo, faz com que os contribuintes

atuem ilicitamente, registrando seus veículos em outros entes federativos, tais como Tocantins, Paraná e Minas Gerais, mais procurados neste quesito.

De fato, os principais alvos tanto da operação "De olho na placa" quanto da nova lei são, sem dúvida alguma, as empresas locadoras e concessionárias de veículos, que, em decorrência de comumente possuírem filiais ou sedes localizadas em outros entes federados do país, optam por registrarem seus veículos naqueles Estados onde a alíquota do imposto em comento é mais baixa. Neste desiderato, a Lei 13.296/2008 prognosticou em seus dispositivos critérios distintos da antiga lei reguladora do IPVA, a fim de que as citadas práticas ilegais ocorridas cotidianamente no Estado pudessem ser, de certa forma, sanadas.

Uma crucial diferença abordada pela mencionada lei estadual condiz à sua hipótese de incidência tributária, especificamente no critério espacial, que até então a Lei nº . 6.606/1989, 
em seu artigo $2^{\circ}$, determinava "devido no local onde o veículo deva ser registrado e licenciado, inscrito ou matriculado, perante as autoridades de trânsito". Estas ilações foram abarcadas no artigo $4^{\mathrm{a}}$ e parágrafos da novata lei, predispondo de maneira minuciosa as considerações a respeito do domicílio do proprietário quando for pessoa natural e jurídica privada ou pública.

\section{O DOMICÍLIO SOB ENFOQUE DAS LOCADORAS E CONCESSIONÁRIAS DE VE- ÍCULOS NA LEI No $N^{\circ}$ 13.296/2008: ANÁLISE DA ILEGALIDADE}

Faz-se oportuno ao estudo a análise detalhada de determinadas disposições da Lei paulista em questão a fim de que se discorra posteriormente acerca de sua legalidade e, neste tocante, quanto ao critério espacial da hipótese de incidência tributária às pessoas jurídicas privadas - concessionárias e locadoras - ponto nevrálgico levantado pelas linhas presentes. Desta forma, dentre outras normas da lei 13.296/2008 que cingem acerca da determinação do domicílio, a que se faz pertinente a reprodução para o escopo do presente trabalho é a seguinte:

\footnotetext{
Artigo $4^{\circ}$ - O imposto será devido no local do domicílio ou da residência do proprietário do veículo neste Estado.

$\S 1^{\circ}$ - Para os efeitos desta lei, considerar-se-á domicílio:

$[\ldots]$

2 - se o proprietário for pessoa jurídica de direito privado:

$[\ldots]$

b) o estabelecimento onde o veículo estiver disponível para entrega ao locatário na data da ocorrência do fato gerador, na hipótese de contrato de locação avulsa; $\S 4^{\circ}$ - No caso de pessoas jurídicas de direito privado, não sendo possível determinar a vinculação do veículo na data da ocorrência do fato gerador, nos termos do item 2 do $\S 1^{\circ}$ deste artigo, presume-se como domicílio o local do estabelecimento onde haja indícios de utilização do veículo com predominância sobre os demais estabelecimentos da mesma pessoa jurídica.

$[\ldots]$

$\S 7^{\circ}$ - Para os efeitos da alínea "b" do item 2 do $\S 1^{\circ}$ deste artigo, equipara-se a estabelecimento da empresa locadora neste Estado, o lugar de situação dos veículos mantidos ou colocados à disposição para locação.
}

Nota-se, conforme explanado em ilações anteriores, que a determinação do critério espacial da hipótese de incidência tributária do IPVA está diretamente vinculada ao local de efetuação do registro do veículo no domicílio de seu proprietário. E, logo, duas leis de caráter nacional vieram a delinear tal acepção, o Código de Trânsito Brasileiro (CTB) e o Código Civil vigentes, interligando assim a interpretação da temática tributária. 
Todavia, conforme leitura do dispositivo supra reproduzido, observa-se especificamente na alínea "b" do parágrafo $1^{\circ}$ do artigo em comento, que a nova lei utiliza-se do critério espacial da habitualidade do veículo para delimitar o critério espacial da hipótese de incidência tributária e não o do domicílio do proprietário.

Noutras palavras, o artigo $4^{\circ}$, parágrafo $1^{\circ}$ da Lei ${ }^{\circ}$. 13.296/2008 estabeleceu em sua redação o que se considera domicílio para os efeitos de sua aplicação, sendo que no caso de pessoas jurídicas de direito privado determinou ser domicílio o "estabelecimento onde o veículo estiver disponível para a entrega ao locatário" (artigo 4", §1 $1^{\circ}, 2$, “b”). Tal assertiva alterou arbitrariamente o conceito de domicílio adotado pelo direito civil, objetivando fazer a incidência do IPVA sobre todos os veículos de locação ou disponíveis em concessionárias em operação no Estado de São Paulo, prevalecendo a idéia de domicílio como o local onde haja indícios de utilização do veículo (artigo $4^{\circ}, \S^{\circ}$ ), sobrepondo-se aos demais estabelecimentos da mesma pessoa jurídica.

Referido paradigma adotado pela novata lei paulista afronta claramente o artigo 75 e parágrafos do Código Civil brasileiro, que delineou em seu texto ser o domicílio da pessoa jurídica o "lugar onde funcionem as respectivas diretorias e administrações, ou onde elegerem domicílio especial no seu estatuto ou atos constitutivos". Neste aspecto, mostra-se nítido o grande equívoco tracejado pela lei estadual $\mathrm{n}^{\circ}$. 13.296/2008, uma vez que desconsiderou sorrateiramente os conceitos abarcados por uma lei nacional a ela hierárquica, configurando de imediato sua ilegalidade.

Em outra vertente, no caso de a pessoa jurídica ter diversos estabelecimentos em lugares diferentes, instituiu ainda o artigo 75, parágrafo primeiro do Código Civil, como domicílio, cada um destes distintos lugares para os atos que neles forem praticados. Ora, grande parte das concessionárias e locadoras situadas no Estado de São Paulo possuem filiais ou mesmo sede em outros Estados da Federação, sendo todas elas, sem distinção, domicílios destas empresas. E, exatamente por isso, é lícito que tais empresas possam escolher o domicílio pelo qual queiram efetuar o registro de seus veículos, tendo em vista ser uma previsão que o Código Civilista permitiu em suas disposições.

Neste sentido, é fundamental frisar que uma lei estadual não pode de forma extremamente impositiva violar o que foi prognosticado no Código de Trânsito Brasileiro (artigo 120) e no Código Civil (artigo 75). A ausência de uma Lei Complementar que regulamente todo e qualquer apontamento acerca do IPVA no ordenamento jurídico brasileiro não dá azo à existência de leis estaduais que discorram ilimitadamente quanto aos critérios da hipótese de incidên- 
cia tributária que já tenham sido, de alguma forma, interligados a conceitos provenientes de leis nacionais ou mesmo pela própria Constituição Federal.

\section{CONCLUSÃO}

A exposição apresentada nas linhas desta pesquisa a respeito do Imposto sobre a Propriedade de Veículos Automotores - IPVA - e todas as pontuações levantadas acerca de sua hipótese de incidência tributária, especialmente condizente ao critério espacial, objetivou o enfoque peculiar do domicílio, aspecto de imensurável relevância para a configuração deste critério.

Salienta-se, neste prisma, a aplicação cabível e necessária do Código de Trânsito Brasileiro e, conseqüentemente, do Código Civil, leis nacionais de fundamental importância para as diretrizes do Direito Tributário, principalmente quando da ausência de leis complementares (artigo 146, I, Constituição Federal) regulamentado imprescindíveis temas, como é o caso do IPVA em comento.

Mediante tais constatações, analisou-se a legalidade quanto ao aspecto do domicílio atinente às locadoras e concessionárias na Lei estadual de São Paulo nº 13.296/2008, nova lei que regulamenta o IPVA. Esta lei, oriunda de recorrentes evasões fiscais e que têm causado certos desconfortos à Secretaria da Fazenda do Estado em razão da perda de arrecadação do imposto nos últimos anos, objetiva cessar com o constante registro de veículos automotores em outros Estados do país cujas alíquotas incidentes são menores, opção mais rentável aos contribuintes e menos benéfica ao Fisco paulista.

Por assim, o legislador, em seu artigo 4a , parágrafo primeiro, 2, alínea "b", suprimiu a faculdade do contribuinte de vincular seu automóvel em outro Estado onde possua estabelecimento, ao determinar que o domicílio, para efeitos da Lei que institui o Imposto sobre a Propriedade de Veículos Automotores, seja considerado onde o veículo foi posto à disposição para locação.

Os parâmetros de domicílio atinentes às empresas locadoras e concessionárias apresentados pela Lei 13.296/2008 afrontam verticalmente preceitos dispostos em impecáveis leis nacionais, ferindo, por óbvio, e, concomitantemente, o direito de escolha do domicílio tributário destas empresas para o eventual registro do IPVA.

Ante ao exposto, pode-se inferir que a Lei paulista em questão objetivou, da forma como foi instituída, aumentar a arrecadação do IPVA através da distorção das características do 
instituto civil do domicílio das pessoas jurídicas, o que deve ser rechaçado pelos intérpretes e aplicadores do direito.

\section{REFERÊNCIAS}

AMARAL, Francisco. Direito Civil: Introdução. Rio de Janeiro: Renovar, 2003.

BRASIL, Código Tributário, 1967. Lei 5. 172 de 25 de outubro de 1966. Disponível em:< http://www.planalto.gov.br/ccivil_03/LEIS/L5172.htm>. Acesso em 30 nov. 2009.

BRASIL, Constituição, 1967. Constituição da República Federativa do Brasil de 1967. Disponível em:

$<$ http://www.planalto.gov.br/ccivil_03/constituicao/Constitui\%C3\%A7ao67.htm>. Acesso em 28 nov. 2009.

, Constituição, 1988. Constituição da República Federativa do Brasil de 5 de outubro de 1988. Disponível em:

$<$ http://www.planalto.gov.br/ccivil_03/Constituicao/Constitui\%C3\%A7ao.htm>.

Acesso em: 28 nov. 2009.

,Código de Trânsito Brasileiro, 1997. Lei 9.503 de 23 de setembro de 1997. Disponível em: <http://www.planalto.gov.br/ccivil/leis/L9503.htm>. Acesso em: 29 nov. 2009.

,Código Civil, 2002. Institui o Código Civil. Disponível em: $<$ http://www.planalto.gov. br/Ccivil_03/LEIS/2002/L10406.htm>. Acesso em: 29 nov. 2009.

, Lei 13.296 de 23 de dezembro de 2008. Estabelece o tratamento tributário do Imposto sobre a Propriedade de Veículos Automotores - IPVA no Estado de São Paulo. Disponível em: $<$ http://info.fazenda.sp.gov.br/NXT/gateway.dll?f=templates\&fn=default.htm\&vid=sefaz tributaria:vtribut>. Acesso em 30 nov. 2009.

CARRAZZA, Roque Antônio. Curso de Direito Constitucional Tributário. São Paulo:Malheiros Editores, 2009.

CARVALHO, Paulo de Barros. Curso de Direito Tributário. São Paulo: Editora Saraiva, 2007.

CARVALHO, Paulo de Barros. Curso de Direito Tributário. 20 ed. São Paulo: Editora Saraiva, 2008.

MAMEDE, Gladston. IPVA. São Paulo: RT, 2002.

MARTINS, Rogério Lindenmeyer Vidal Gandra da Silva. O Perfil do Imposto sobre a Propriedade de Veículos Automotores - IPVA. In: MARTINS, Ives Gandra. Curso de Direito Tributário. 8 ed. São Paulo: Saraiva, 2001. 
MARTINS, Rogério Lindenmeyer Vidal Gandra da Silva. O Perfil do Imposto sobre a Propriedade de Veículos Automotores - IPVA. In: MARTINS, Ives Gandra. Curso de Direito Tributário. 9 ed. São Paulo: Saraiva, 2007.

SABBAG, Eduardo de Moraes. Elementos do Direito. São Paulo: Siciliano Jurídico, 2004.

PAULSEN, Leandro. Direito Tributário: Constituição e Código Tributário à Luz da Doutrina e da Jurisprudência. Porto Alegre: LiVraria do Advogado: ESMAFE, 2007.

SILVA, Paulo Coimbra. Perfil Constitucional da Hipótese de Incidência do IPVA. Revista Fórum de Direito Tributário RFDT. set/out 2006. n 23. ano 4. pp. 138/153. 